
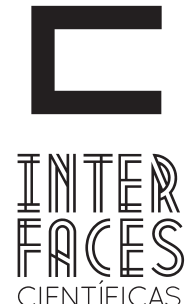

EXATAS E TECNOLÓGICAS

ISSN IMPRESSO - 2359-4934

ISSN ELETRÔNICO - 2359-4942

\title{
ANÁLISE DAS INTERRUPÇ̃̃ES NO PROCESSO DE LAMINAÇÃO DE UMA SIDERÚRGICA ATRAVÉS DE FERRAMENTAS DE QUALIDADE
}

Diego Coelho Medeiros ${ }^{1}$

Suzana Arleno Souza Santos ${ }^{3}$
Gustavo Henrique Cordeiro Stender ${ }^{2}$

identificar as variáveis presentes neste processo de melhoria. Por meio de dados quantitativos e qualitativos resultantes da aplicação destes conceitos, é possível evidenciar os ganhos em produtividade e qualidade desta operação.

\section{PALAVRAS-CHAVE}

Qualidade. Melhoria. Processo. Siderurgia. 


\section{ABSTRACT}

This study aims to analyze a process improvement in a steel production line of the city of Rio de Janeiro. Highlighting the importance of using quality tools and exercise leadership in the search for solutions to minimize excess production stoppages for rework. Thus there is a contextualization of the steel industry history and the evolution of quality concepts in order to identify the variables present in this improvement process. Through quantitative and qualitative data resulting from the application of these concepts, you can highlight the gains in productivity and quality of this operation.

\section{KEYWORDS}

Quality. Improvement. Process. Steel Industry.

\section{RESUMEN}

Este studio tiene como objetivo analizar la mejora de procesos en una línea de producción de acero de la ciudad de Río de Janeiro. Destacando la importancia del uso de herramientas de calidad y ejercer el liderazgo en la búsqueda de soluciones para reducir al mínimo las paradas de producción en exceso para la reanudación. Así, hay una contextualización de la historia de los aceros y la evolución de los conceptos de calidad con el fin de identificar las variables presentes en este proceso de mejora. A través de datos cuantitativos y cualitativos que se derivan de la aplicación de estos conceptos, se puede destacar los aumentos de la productividad y la calidad de esta operación.

\section{PALABRAS CLAVE}

Calidad; Mejora; Proceso; El Acero. 


\section{INTRODUCÃO}

A indústria da construção envolve elevado número de processos e produtos, representando um dos mais significativos setores econômicos para a grande maioria dos países, principalmente nos países em desenvolvimento. No Brasil, estima-se que a Construção Civil seja responsável por aproximadamente $15 \%$ do Produto Interno Bruto (PIB), empregando quase 55\% e gerando milhões de empregos diretos e indiretos (SOUZA, 2005).

A ineficiência produtiva da construção civil resulta em prejuízos ambientais, sociais e econômicos, os quais afetam diretamente a competitividade das organizações e a qualidade de vida de seus colaboradores. As estratégias voltadas para o desenvolvimento de técnicas de gerenciamento de risco aplicado ao negocio tornam-se, portanto, questões fundamentais. Para reduzir o numero de acidentes relacionados ao trabalho e manter a redução deste, é necessário fazer da segurança um estilo de viver. É preciso envolver as pessoas nas atividades diárias de forma consistente com a visão de uma cultura de segurança total.

Nos últimos anos, vem sendo realizados grandes esforços no sentido de introduzir a Qualidade Total na construção civil. Porém ocorre que a construção possui características singulares que dificultam a aplicação das teorias modernas de qualidade.

Podemos citar algumas peculiaridades da construção civil, tais como, é uma indústria tradicional, com enorme resistência as alterações, a precisão com que os trabalhadores exercem suas funções, em geral, é muito menos que as demais indústrias; a construção na maioria das vezes, realiza seus trabalhos sob intempéries.

Segundo estudos, o comportamento de risco que as pessoas praticam no dia a dia, é a principal resposta sobre a causa dos acidentes. 0 comportamento das pessoas é o ponto crítico para a melhoria do desempenho e deve ser direcionado para se obter a excelência em segurança. Mais de 70 anos de pesquisa e observação da teoria de Heinrich, desde 1930 até hoje, confirmam que os comportamentos de risco ou inseguros envolvidos na maioria dos acidentes (MASSERA, 2005).

Segundo Massera (2005), a excelência em segurança e saúde do trabalho não pode ser alcançada apenas com programas, mas com mudanças contínuas de comportamento. Nos últimos 70 anos, as empresas têm focado quase que exclusivamente, Engenharia, Treinamento e Punição. Em grande parte, os profissionais de segurança assumiram este posicionamento. Agora é o momento de construir a cultura, estratégia organizacional, liderança com desempenho e comportamento organizacional, que são as verdadeiras fontes de acidentes. A fundamentação teórica desta pesquisa apresenta a importância do envolvimento de toda a força de trabalho para o sucesso no gerenciamento de risco. Fatores comportamentais e pessoais representam a dinâmica humana de segurança ocupacional (GELLER, 2004).

Complementando a realidade acima apresentada, os autores desta pesquisa identificam a necessidade de disseminar a importância da aplicação de ferramentas para o gerenciamento de risco na indústria da construção civil. Busca-se, também, identificar o nível da organização (estratégico, tático e operacional) que é responsável pelas atividades do diagrama do gerenciamento de risco (TRINDADE, 2014).

Os empreendimentos deste segmento são únicos, utilizam mão de obra de baixa qualidade e, por menos que sejam, envolvem grandes quantidades de insumos. Estes fatores implicam na dificuldade para o gerenciamento de empreendimento e, principalmente, para o gerenciamento dos riscos deste empreendimento.

Em pesquisa informal nos canteiros de obras (obras isoladas e particulares), constatou-se que 
98\% das obras são fornecidos os EPIs necessários aos colaboradores, mas apenas $15 \%$ destes colaboradores usam os equipamentos, e ainda, destes $15 \%$ que usam, $5 \%$ usam de maneira errada ou usam parcialmente. Por se tratar de obras isoladas (contratação direta do proprietário), não existe um Mestre de Obras, e muito menos um Técnico em Segurança do Trabatho, o que dificulta a fiscalização. Portanto neste tipo de obras, que é em número significativo na nossa Cidade, é que existe o maior número de acidentes de Trabalho. E está diretamente ligado à falta de uso dos EPIs ou o mau uso dos mesmos (TRINDADE, 2014).

Esta pesquisa foi feita no método informal em obras de médio e pequeno porte, ou seja, direto nos canteiros de obra, aonde se chegou às conclusões acima mencionadas.

\section{REVISÃO DA LITERATURA}

\subsection{GESTÃO DE PESSOAS}

Krause (2004) observa que numa cultura de segurança todos se sentem responsáveis pela segurança e a busca a todo o momento. Os empregados, vão além de suas obrigações para identificarem comportamentos e condições de risco, para, intervindo, corrigi-los.

Em uma cultura de segurança, a segurança não é uma prioridade que pode ser mudada, dependendo das exigências da situação; ao contrário, a segurança é um valor que está ligado a todas as outras prioridades, porém, isto é mais fácil de ser feito. Geller (2004) afirma que a segurança deveria estar ligada, de modo consistente, a todos os aspectos do trabalho, quer se referindo a qualidade, produtividade, lucratividade ou eficiência.

A segurança deveria ser bem mais do que usar "equipamento de proteção pessoal", "desligar a força", "verificar possíveis riscos com equipamento!" e "manter a área de trabalho em ordem!" A segurança deveria ser um valor que os funcionários trariam a todos os car- gos, apesar das prioridades ou exigências da tarefas. Deveria ser uma regra tácita (norma social), que se seguisse independentemente da situação.

Segundo Geller:

PESSOAS: Conhecimento, Habilidade, Destreza, Inteligência, Motivação, Personalidade;

AMBIENTE: Equipamentos, Ferramentas, Máquina, Manutenção, Temperatura, Engenharia;

COMPORTAMENTO: Aceitar, preparar, comunicação.

Para Geller (1994), a cultura de segurança requer atenção contínua nos três domínios acima mencionados. Fatores ambientais, Fatores pessoais e Fatores comportamentais. Esses fatores são dinâmicos e mudanças interativas em um fator podem, no final, causar impacto nos outros dois. Por exemplo, comportamentos que reduzem a probabilidade de acidentes muitas vezes envolvem mudanças ambientais e produzem atitudes consistentes com os comportamentos de segurança, especialmente se esses comportamentos são percebidos como voluntários. Em outras palavras, quando os funcionários decidem agir com segurança, eles incorporam a atitude mental de segurança e tais comportamentos frequentemente resultam em mudanças ambientais.

A melhor maneira de conquistar uma efetiva cultura de trabalho que contemple as disciplinas mencionadas acima e tratá-las de forma integrada. Este estudo visa evidenciar a necessidade de mudança na cultura de segurança do trabalho estabelecida hoje no mercado da construção civil. Conforme as referências bibliográficas pesquisadas, o atual cenário deste setor ainda apresenta-se passivo e reacionista. Para sua melhoria, é necessário promover uma cultura integrada baseada em atitudes prevencionistas e pró-ativas. Esta mudança poderá acontecer, basicamente, por uma efetiva troca de informações e experiências, assim como treinamentos, conscientização de conteúdo e aplicação prática na construção civil, a todos os níveis da organização (estratégico, tático e operacional), e que gere sensibilização, reciclagem e aperfeiçoamento de toda a mão de obra. 
A implantação da NR-18 ajudou muito a melhorar a qualidade das obras e também a qualidade de vida de seus trabalhadores. De objetivo, ficou a diminuição drástica de acidentes no setor, principalmente no que se refere ao total de acidentes registrados entre os anos de 2002 e 2003, já que no caso de óbitos, a redução não foi tão significativa.

Apesar da diminuição dos índices ao longo dos anos, o número de acidentes, principalmente o de óbitos, ainda, é expressivo na indústria da construção o que gera a necessidade de uma atividade gerencial mais atuante e com foco preventivo em suas ações.

\subsection{GERENCIAMENTO DE RISCOS}

Os gestores têm cometido um grande equívoco, quando analisam a segurança do trabalho, separadamente, dos aspectos administrativo, econômico, ambiental e social das empresas. Atualmente, é notória a falta de compreensão por parte dos executivos, dos custos dos acidentes e dos outros acontecimentos que ocasionam perdas, comprometendo a imagem da empresa e muitas vezes a sua sobrevivência. Poucos são os executivos, que os mesmos fatores, que ocasionam acidentes são também criando perda de eficiência bem como problemas de qualidade, custo e de imagem da empresa (SOUZA, 2000). É necessária uma boa política de prevenção de acidentes, adequada para atuar, corrigir e prevenir os pequenos acidentes e incidentes.

Observando os dados da Fundacentro, o número de acidentes que ocorre anualmente na indústria da construção civil é inaceitável. Segundo Souza (2000) não podemos aceitar empresas que relutam adotar políticas e práticas preventivas. 0 comportamento das pessoas deve passar de reativo para pró-ativo. As ações devem ser de antecipação e não mais de correção.

\subsubsection{DIAGRAMA DE GERENCIAMENTO DE RISCO E SEUS REQUISTTOS}

Segundo a AS/NZS 4360, o diagrama apresentado a seguir representa o conceito do gerenciamento de risco que é proteger o patrimônio da empresa, por meio da identificação dos riscos, sejam relacionados a propriedade, ao pessoal, aos processos, ao produto, ao equipamento ou ao ambiente. Após a identificação, os riscos são analisados em termos de severidade e frequência avaliados quanto à categoria do risco. A alta administração trata o risco conforme a política de risco da empresa, com o objetivo de reduzir, evitar, assumir ou repassar o risco à seguradora. Com base nestas informações, a empresa elabora ou atualiza o Programa de Prevenção e Controle de Perdas. Este programa busca maximizar os resultados da empresa, otimizando o uso de recursos humanos, materiais ou financeiros (Figura 1).

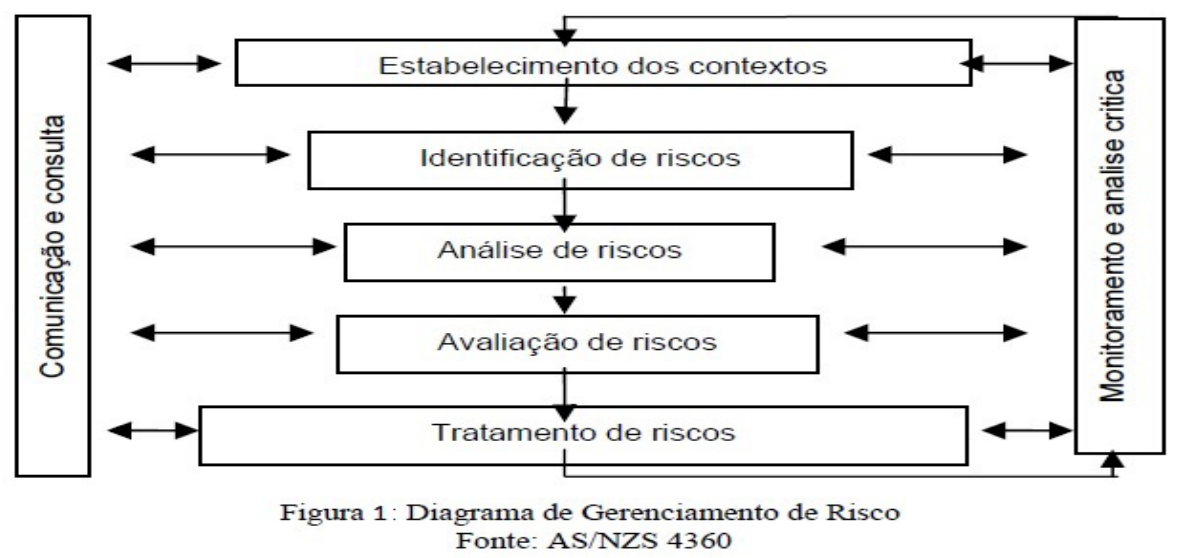

Interfaces Científicas - Exatas e Tecnológicas - Aracaju • V.1 • N.1 • p. 67 - 77 • Fev. 2015 
A alta administração da organização, junto com as partes interessadas, deve desenvolver uma política organizacional de gestão de um mecanismo de suporte, a fim de fornecer uma estrutura para a condução de um programa de gestão de riscos mais detalhado. Segundo AS/NZS, os requisitos para a gestão de riscos são: política de gestão de riscos, responsabilidades e autoridades, programa de implementação e analise critica pela direção.

A direção da organização deve assegurar que seja realizada uma análise critica do sistema de gestão de riscos a intervalo especificados, que permitam garantir sua continua adequação e eficácia em atender os requisitos e as normas de gerenciamento de riscos, como por exemplo, a AS/NZS 4360. A gestão de risco é um processo de melhoria contínua que a cada ciclo deve ser atualizada, conforme os resultados do monitoramento e análise crítica.

Atualmente, as leis, as normas e a própria sociedade exige que as organizações atuem de forma sustentável. Uma medida básica de comportamento da alta direção com esta questão, que é um bom programa de comunicação e consulta às partes interessadas envolvidas internas e externas, conforme apropriado, em cada etapa do processo de gestão de riscos e em relação ao processo como um todo.

\subsection{ANÁLISE PRELIMINAR DE RISCOS (APR)}

Este método é utilizado para análise inicial dos riscos e caracteriza-se por apresentar informações qualitativas. A sua aplicação é ideal na fase de projeto ou desenvolvimento de qualquer novo processo, produto ou sistema (SOUZA, 2000).

A APR tem como objetivo determinar os riscos e as medidas preventivas antes da fase operacional. A metodologia aplicada é a revisão geral de aspectos de segurança, por meio de um formato padrão, levantadas causas e efeito de cada risco, medidas e prevenção ou correção ou categorização dos riscos. Este método facilita a priorização das ações preventivas e corretivas e permite revisões nos projetos em tempo hábil, proporcionando maior segurança.

Além disso, a APR permite previamente estimar qualitativamente o risco associado a cada sequência de eventos, a partir da estimativa da frequência e da severidade da sua ocorrência. A APR avalia qualitativamente a severidade e a frequência de ocorrência dos perigos identificados. As medidas utilizadas devem refletir as necessidades e a natureza da organização e da atividade em estudo. Esta avaliação deve ser feita por um especialista. Estes dois fatores são os responsáveis pela classificação do risco (Quadro 2).

Quadro 1

\begin{tabular}{|c|c|c|c|c|c|}
\hline \multirow{2}{*}{ Freqüência } & \multicolumn{5}{|c|}{ Severidade } \\
\cline { 2 - 6 } & I & II & III & IV & V \\
\hline A & 2 & 2 & 1 & 1 & 1 \\
\hline B & 3 & 2 & 2 & 1 & 1 \\
\hline C & 4 & 3 & 2 & 2 & 1 \\
\hline D & 4 & 4 & 3 & 2 & 2 \\
\hline E & 4 & 4 & 3 & & 1 \\
\hline
\end{tabular}

Fonte: AS/NZS 4360, Adaptado pelos autores 
O Quadro 2 apresenta a definição das categorias de risco que são identificadas conforma matriz de analise qualitativa do risco que confronta o nível de frequência $x$ o nível de severidade.

Quadro 2: Definição das Categorias do Risco

\begin{tabular}{|l|}
\hline \multicolumn{1}{|c|}{ Categoria do Risco } \\
\hline 1-Risco extremo, necessária uma ação imediata \\
\hline 2-Risco alto, necessária a atenção da alta administração \\
\hline 3-Risco moderado, a responsabilidade da alta administração deve ser especificada \\
\hline 4-Risco baixo, gerenciando por procedimentos de rotina \\
\hline
\end{tabular}

Fonte: AS/NZS 4360, Adaptado pelos autores

A classificação do risco é uma informação muito importante para a análise preliminar do risco, pois indicará a ordem de prioridade que a organização deverá alocar recursos, seja pessoal ou financeiro, e as medidas preventivas.

No que diz respeito à natureza trata-se de uma pesquisa aplicada devido ao fato de objetivar a geração de conceitos e modelos para aplicação prática, na indústria da construção civil, relacionada a gestão de pessoas e gerenciamento de risco.

É uma pesquisa qualitativa, pois as técnicas de coleta de dados utilizadas forma a observação participante dos autores nas atividades deste estudo, as análise, comparações e interpretações de documentos, dados e informações disponíveis em literatura especializada. Os autores pesquisaram a fundamentação teórica em artigos, livros e dissertações, com o intuito de compreender os aspectos relacionados ao gerenciamento de risco na indústria da construção civil, bem como a gestão de pessoas aplicadas neste setor. Analisam-se os resultados das APRs que foram elaboradas para as atividades da construção civil que representam o maior risco de acidentes e que estatisticamente apresentam o maior número de acidentes de trabalho.
A partir da compreensão desses conceitos, os autores ainda apresentam uma proposta para o desenvolvimento de um plano de segurança, identificando os níveis organizacionais com maior grau de envolvimento para o desenvolvimento das etapas do diagrama de gerenciamento de risco.

\section{ANÁLISE PRELIMINAR DE RISCO (APR) EM ATI- VIDADES DA INDUSTRIA DA COSNTRUÇ̃̃O CIVIL}

\subsection{CONSIDERACÕES INICIAIS}

Neste capitulo, a partir das experiências dos autores, analisa-se os resultados das APRs que formas elaboradas pelos autores para as seguintes atividades: planos elevados e central de carpintaria. A escolha foi baseada nas atividades mais significativas na Construção Civil quanto ao risco de acidentes, utilizando dados levantados pela DRT-RJ e a Fundacentro.

\subsection{IDENTIFICAÇÃO DAS ATIVIDADES PARA ELABORAÇÃO DA APR}

\subsubsection{DTR-RJ - DELEGACIA REGIONAL DO TRABALHO DO RIO DE JANEIRO: SITUAÇ̃̃OO DE GRAVE E IMINENTE RISCO}

Com o objetivo de elevar o padrão das condições de trabalho nos Canteiros de Obras no Estado do Rio 
de Janeiro, tendo como foco a preservação da dignidade e da integridade física do trabalhador, foi anunciado na sede da DRT-RJ, o Programa Especial de Fiscalização na Construção Civil.

Um Termo de Notificação Padrão foi elaborado pela Seção de Segurança e Saúde do Trabalhador (SEGUR) e pela Seção de Fiscalização do Trabalho (SFISC), para que uma equipe da DRT-RJ desenvolvesse ação de fiscalização nos canteiros de obras, envolvendo a Construtora principal, as subempreiteiras e prestadoras de serviços.

As ações fiscais determinaram a fiscalização das mesas de entendimentos ou penalidades que empreenderam atuação, interdição ou embargo em "Situações de Grave e Iminente Risco" quanto a serra circular (carpintaria), proteção contra queda de alturas (planos elevados), andaimes, instalações elétricas, movimentação e transporte de materiais e pessoas.

\subsection{ELABORAÇÃo DA ANÁLISE PRELIMINAR DE RISCO}

A construção civil, por suas características peculiares, tem uma condição de insegurança inerente a sua própria atividade, assim como os atos inseguros que a maioria dos lideres, sejam engenheiros, mestres de obras e encarregados, assumem em suas atividades diárias, sem avaliarem os riscos das atividades que desenvolvem, expondo a si próprios e a seus colegas de trabalho a riscos desnecessários.

As atividades ocorrem, na grande maioria, sem uma análise, sem um estudo prévio do que será executado e quando essa análise ocorre, invariavelmente, a segurança é relegado a um segundo plano. Em resumo, preocupa-se com a madeira, a barra de aço, com a necessidade de se ter um ponto de energia na frente da obra, com a urgência de se estar a 5 metros de altura para concluir a forma de um pilar, mas as condições de segurança, que envolvem desde uma verificação das condições e estado do insumo utilizado, passando pelas ferramentas adequadas para o servi- ço especifico, até o adequado dimensionamento de um Equipamento de Proteção Coletiva (EPC) ou Equipamento de Proteção Individual (EPI), que são pouco levado em consideração.

Segue, abaixo, a análise das atividades e dos resultados das APRs que foram elaboradas para as atividades da construção civil.

\subsubsection{PLANOS ELEVADOS}

Na atividade da indústria da construção civil existem inúmeras situações de elevado risco, inerentes à própria atividade. A falta de proteção em situação de risco de quedas de altura constitui-se na causa principal do número de acidentes fatais, vitimando centenas de trabalhadores a cada ano, como indicam as estatísticas no Brasil.

Na indústria da construção civil, destacam-se as atividades a seguir, as quais envolvem riscos de queda de altura: partes periféricas de lajes, aberturas de piso, vãos de acesso às caixas de elevadores, vãos de escadarias ou rampas, serviços executados em sacadas e/ou varandas, construção ou manutenção de telhados e/ou coberturas, montagem e desmontagem de andaimes fachadeiros, montagem ou desmontagem de torre de elevadores de obras, trabalhos em andaimes suspensos, montagem de elementos estruturais (pré-moldados, metálicos), trabalhos em confecção de formas, ferragens e concretagem de estruturas de lajes, manutenção de fachadas de edifícios e inspeção e manutenção de chaminés.

Os riscos de quedas de trabalhadores ou projeções de materiais podem ser neutralizados por meio de Medidas de Proteção Coletiva e/ou medidas de proteção individual. Os EPIs e EPCs recomendados em geral são: uniforme completo de mangas compridas, luva de vaqueta mista, botina de couro, cinto de segurança tipo paraquedista com dois talabartes, isolamento da área de trabalho com fita zebrada, escada de acesso presa ao quadro horizontal, assoalho de madeira completo e travado e guarda corpo. 


\subsubsection{CENTRAL DE CARPINTARIA}

Os trabalhos na central de carpintaria e as atividades executadas pelos carpinteiros de uma forma geral na indústria da construção civil são a fabricação de painéis para forma, a montagem e a desmontagem das mesmas, formas essas utilizadas para estrutura de concreto como pilares, vigas e lajes, dede concepções simples como uma simples cisterna, até estruturas arrojadas como Pontes e outras grandes obras.

Os EPIs básicos de um carpinteiro são: capacete, luva, bota de couro e óculos de segurança. No caso de operadores de serra circular, outros EPIs se fazem necessários: avental de raspa, protetor facial, protetor auricular tipo concha e máscara descartável. Os EPCs considerados mínimos são: proteção das lâmpadas, cutelo divisor, coifa de proteção, caixa de coleta de serragem e extintor de incêndio tipo água pressurizada e $\mathrm{CO} 2$ ou PQS.

O potencial de acidentes ou perdas é muito grande em uma central de carpintaria principalmente com relação a quedas de mesmo nível, risco de incêndio, ruído, lesão e corte de membros superiores, projeção de partículas, postura inadequada, uso de ferramentas inadequadas e defeituosas e levantamento e transporte manual de peso.

As condições mínimas que uma central de carpintaria devem ter, envolvem uma instalação com cobertura apropriada, no caso de risco de quedas de objetos nos trabalhadores, uma sinalização clara com respeito a correta utilização dos EPIs relacionados as atividades de uma central de carpintaria, sinalização de que é proibido fumar na central, iluminação adequada, piso firma, nivelado e antiderrapante, um extintor de incêndio tipo CO2 próximo a mesa da serra circular, assim como um estudo prévio do layout e da melhor localização desta central de carpintaria, no intuito de preservar os funcionários das demais instalações em relação ao ruído, evitando assim a obrigatoriedade de que esse outros funcionários usem EPIs devido a central carpintaria.

\subsection{ANÁLISE CRÍTICA}

Após análise das APRs, constatou-se que para o sucesso de um plano de segurança é necessário a sinergia de todos os níveis organizacionais. Conforme a tabela abaixo, as medidas preventivas/recomendações das APRs são, fundamentalmente, pertinentes às atividades de execução no canteiro de obra, sob responsabilidade do nível operacional, evidenciando a importância deste nível para implementação eficaz do plano de segurança. Constata-se, também, que é necessário um alto grau de comprometimento dos níveis estratégicos e táticos, pois estes são os responsáveis respectivamente por assegurar e garantir as práticas de segurança. Estatisticamente, relacionam-se as medidas preventivas/recomendadas das APRs com níveis organizacionais e os resultados comprovam estas conclusões (FRANÇA 2005).

Quadro 3: Análise das APR's - Percentual de Responsabilidade dos Niveis Organizacionais

\begin{tabular}{|c|c|c|}
\hline Nível & Função / cargo & Percentual de Responsabilidade \\
\hline Estratégico & Diretoria & $1,7 \%$ \\
\hline Tático & Gerentes e Engenheiros & $25,6 \%$ \\
\hline Operacional & $\begin{array}{c}\text { Mestres, encarregados e mão de obra } \\
\text { operacional }\end{array}$ & $48,8 \%$ \\
\hline Todos & Todos & $24 \%$ \\
\hline
\end{tabular}

Fonte: os autores 
A utilização da ferramenta APR nas atividades indicadas anteriormente, revela-se uma contribuição importante para a gestão de segurança do trabalho na indústria da construção civil, a partir do momento em que ela é vista como um elemento fundamental para um plano de segurança eficaz. Entretanto, o grande problema é que na prática, a realidade deste setor continua com um discurso de improvisação e atitude de autossuficiência, perante aos perigos e riscos.

A alta administração que deveria dar exemplo para a força de trabalho, ainda, preza pelo objetivo de produzir a qualquer custo. Por este motivo, os autores buscam contribuir com uma proposta de plano de segurança que tem como objetivo identificar o grau de comprometimento de todos os níveis da organização e a sinergia entre eles. Muitos gestores falham em considerar funcionários como principais causadores de acidentes, por isso a necessidade de mudança na cultura da segurança. Tal modo de pensar é o grande obstáculo para o sucesso de implementação de novos modelos de gestão.

\section{CONCLUSÃO}

0 principal pré-requisito para efetivação de qualquer sistema de gestão de segurança do trabalho é o comprometimento de todos, desde a alta administração até os operários. Porém, a indústria da construção civil preserva, em grande parte das empresas, o gerenciamento tradicional não participativo. Por este motivo, para o desenvolvimento e implementação de um sistema de gestão de segurança do trabalho realmente efetivo, é necessária a sensibilização da alta administração e o foco na prevenção.

Com intuito de promover melhorias nesta área, as legislações de segurança têm sido aprimoradas, porém a constância dos altos índices de acidentes refle- te a necessidade de mudança de abordagem pontual para abordagem sistêmica. Desta forma, passa-se a ter uma visão macro da organização, integrando todos os níveis hierárquicos de forma a proporcionar o desenvolvimento e a consecução de um objetivo maior, garantir a saúde e a segurança de todos os elementos da organização.

Isoladamente as medidas preventivas recomendadas nas APRs, por si só, não promovem a melhoria no processo produtivo quanto à redução dos riscos de acidentes, por se tratarem de ações pontuais e não sistêmicas e em momento inadequado do seu uso. Os autores ratificam a necessidade de desenvolvimento da APR antes da elaboração do plano de segurança, caso contrario, a função prevencionista de um plano não estará sendo atendida.

A aplicação desta ferramenta na fase de projeto ou de desenvolvimento de qualquer novo processo, produto ou sistema na indústria da construção civil é fundamental para que se cumpra o objetivo de determinar a categoria dos riscos e as medidas preventivas antes da fase operacional, permitindo revisões do projeto em tempo hábil no sentido de promover maior segurança para o trabalhador, o meio ambiente e o patrimônio da organização.

Com o foco na prevenção, a análise preliminar do risco poderá apresentar os seguintes benefícios para a indústria da construção civil: reduzir a frequência e a gravidade de eventos indesejados no canteiro de obra; adequar o seguro aos riscos dos empreendimentos; reduzir e/ou eliminar as indenizações/multas provenientes a danos ao meio ambiente, identificar necessidades de treinamentos; detectar as deficiências e otimizar os gastos com manutenção; preservar a imagem da construtora; manter o ambiente de trabalho adequado quanto a segurança e priorizar as tomadas de decisões dos investimentos necessários em prevenção. 


\section{REFERÊNCIAS}

BRASIL. Ministério do Trabalho. Norma Regulamentadora $\mathrm{n}^{\circ} 18$ (NR-18) Condições e Meio Ambiente de Trabalho na Indústria da Construção, Brasília, 7 de julho de 2005.

FRANÇA, S. L. B.; C. C.; MOREIRA, L. C. P.; CERBINO, R. Análise preliminar de risco como fator crítico de sucesso para estruturação de um plano de segurança da construção civil. 2005. Monografia (Especialização em Engenharia de Segurança do Trabalho), LATEC/UFF, 2005.

GELLER, E. SCOTT. Ten Principles for achieving a total safety culture. Professional Safety. American Society of Safety Engineers, 2004.
KRAUSE, T. R. Segurança e qualidade: os dois lados da mesma moeda. São Paulo: Quality Progress, 2004.

MASSERA, Carlos. Soluções em comportamento, prevenção de acidentes e ergonomia. Revista Proteção, Novo Hamburgo-RS, 2005.

SOUZA, Carlos Roberto Coutinho. Análise e gerenciamento de riscos em processos industriais. Apostila do Curso de Especialização em Engenharia de Segurança do Trabalho. Universidade Federal Fluminense, 2000.

SOUZA, R. de; EKEBEIAN, G.; SILVA, M. A C.M.T.; SANTOS, M.M. Sistemas de gestão da qualidade para empresas construtoras. São Paulo: Sinduscon/SP, 2004.

SOUZA, R. Sistema de gestão da qualidade para empresas construtoras. São Paulo: Pini, 2005. 